ARTIFICIAL SATELLITES, Vol. 53, No. $1-2018$
DOI: $10.2478 /$ arsa-2018-0004

\title{
KINEMATIC-PPP USING SINGLE/DUAL FREQUENCY OBSERVATIONS FROM (GPS, GLONASS AND GPS/GLONASS) CONSTELLATIONS FOR HYDROGRAPHY
}

\author{
Ashraf Farah \\ Associate Professor,College of Engineering, Aswan University, Aswan, Egypt. \\ ashraf_farah@aswu.edu.eg
}

\begin{abstract}
Global Positioning System (GPS) technology is ideally suited for inshore and offshore positioning because of its high accuracy and the short observation time required for a position fix. Precise point positioning (PPP) is a technique used for position computation with a high accuracy using a single GNSS receiver. It relies on highly accurate satellite position and clock data that can be acquired from different sources such as the International GNSS Service (IGS). PPP precision varies based on positioning technique (static or kinematic), observations type (single or dual frequency) and the duration of observations among other factors. PPP offers comparable accuracy to differential GPS with safe in cost and time. For many years, PPP users depended on GPS (American system) which considered the solely reliable system. GLONASS's contribution in PPP techniques was limited due to fail in maintaining full constellation. Yet, GLONASS limited observations could be integrated into GPS-based PPP to improve availability and precision. As GLONASS reached its full constellation early 2013, there is a wide interest in PPP systems based on GLONASS only and independent of GPS. This paper investigates the performance of kinematic PPP solution for the hydrographic applications in the Nile river (Aswan, Egypt) based on GPS, GLONASS and GPS/GLONASS constellations. The study investigates also the effect of using two different observation types; single-frequency and dual frequency observations from the tested constellations.
\end{abstract}

Keywords: GPS/GLONASS, Precise Point Positioning, Kinematic, Single/dual, Hydrography

\section{INTRODUCTION}

Hydrography is the branch of applied science which deals with the measurement and description of the physical features of the navigable portion of the earth's surface [seas] and adjoining coastal areas, with special reference to their use for the purpose of navigation. Global Positioning System (GPS) is ideally suited for inshore and offshore positioning because of its high accuracy and the short observation time required for a position fix. The horizontal position requirements for marine surveys vary between a few decimetres and several tens of metres. To meet these requirements, different observation and processing techniques using pseudo-ranges and/or carrier phases must be employed (IHO, 2005).

Precise point positioning (PPP) is an enhanced single point positioning technique for code or phase measurements using precise orbits and clocks instead of broadcast data. PPP became 
viable with the existence of the extremely precise ephemerides and clock corrections, offered by different organizations such as the IGS (International GNSS Service) (Zumberge et al., 1997; Bisnath S. and Gao Y., 2008; Geng et al., 2010). The PPP technique (Zumberge et. al., 1997) aims at correcting the observations errors and overcome the DGPS limitations. Current PPP techniques are mainly based on GPS which considered the solely reliable system for many years, GLONASS limited observations could be integrated into GPS-based PPP to improve availability and precision (Tolman et al., 2010). As GLONASS reached its full constellation early 2013 (GLONASS, 2017), there is a wide interest in the development of GPS and GLONASS combined PPP systems for improved precision and reliability (Cai and Gao, 2013) .

For the marine positioning, the use of GNSS differential positioning is limited to coastal areas where reference stations can be installed. PPP allows worldwide coverage for offshore applications, extending the GNSS precise positioning capability to remote areas and has the potential to reduce costs and logistical requirements in marine surveying. Many oceanographic applications and studies may arise if centimetre level accuracy can be extended to oceanic areas. Examples of such applications are the direct georeferencing of shipborne or buoy sensors, sea level and wave height determination, ship dynamics determination, motion compensation, control of maritime works and atmosphere sensing (Marreiros, 2012).

Many studies have been investigated the performance of kinematic-PPP for hydrographic applications. (Abdallah and Schwieger, 2015) compared the kinematic PPP solution using dual frequency GPS observations with the DGPS solution for two hydrographic trajectories observed on the Rhine River (Germany). The PPP and DGPS solutions were obtained using Bernese GNSS software. The delivered Standard deviation from this research was $4.00 \mathrm{~cm}$, $2.50 \mathrm{~cm}$, and $6.00 \mathrm{~cm}$ for East, North, and height coordinates, respectively. (Abdallah, 2016) compared the kinematic PPP solution using dual frequency GPS observations with the DGPS solution for two hydrographic trajectories observed on the Nile River (Aswan, Egypt). The average achieved RMS errors for the PPP solution showed $2.5 \mathrm{~cm}$ for East, 3.50 for North, and $5.50 \mathrm{~cm}$ for height.

\section{TEST STUDY}

A kinematic track of $27.5 \mathrm{~km}$ (Figure 1) was observed using combined GPS/GLONASS dual frequency observations (4 hr, $34 \mathrm{~min}$.) on (6/3/2017) (GPS day 19391) at the Nile river, Aswan, Egypt. Aswan is a city sited in south Egypt $\left(24.0889^{\circ} \mathrm{N}, 32.8997^{\circ} \mathrm{E}\right)$ using Leica Viva GS15 receiver (Leica Viva, 2017) with $1 \mathrm{sec}$ observation recording interval and 10o elevation mask angle. The observations file was undergoing quality check using the software TEQC "translate, edit, quality check" GNSS data tool (TEQC, 2017). The observations file was divided into two categories. The first category includes dual frequency observations from both constellations. The first category includes three files; combined (GPS/GLONASS) file, GPS-only file and GLONASS-only file.The second category includes single frequency observations from both systems. The second category also includes three files; combined (GPS/GLONASS) file, GPS-only file and GLONASS-only file. The PPP solutions were estimated for the six files from two categories through Canadian Spatial Reference System (CSRS) Precise Point Positioning (PPP) service (Table 2 \&3) (CSRS-PPP, 2017). 


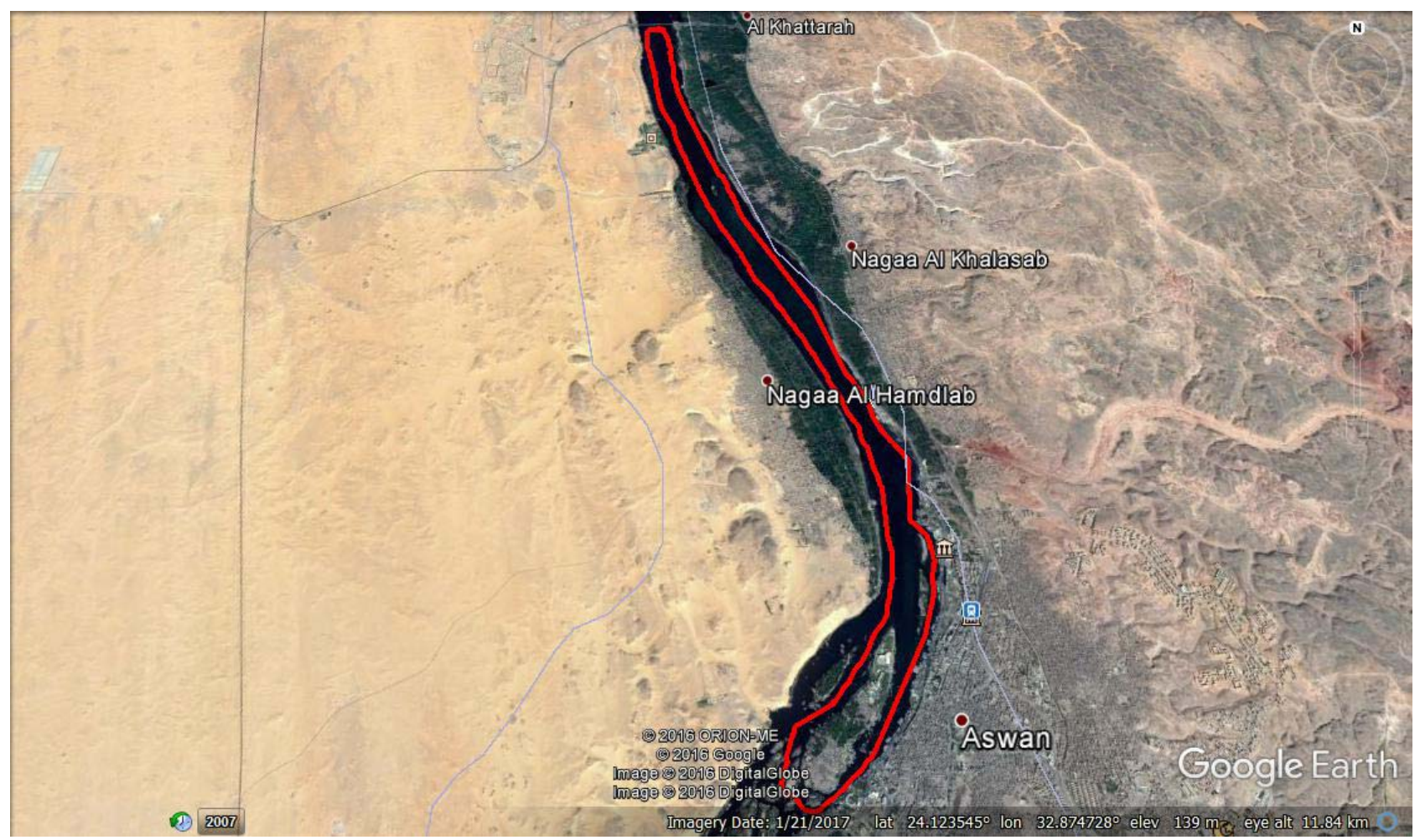

Fig. 1. The Nile River observed kinematic track using dual-frequency combined (GPS/GLONASS) (6/3/2017) (GoogleEarth, 2017).

Table (1) shows the average number of visible satellites and Dilution of Precision (DOP) values; Horizontal DOP, Vertical DOP and Position DOP (HDOP\&VDOP\&PDOP) during observations collection period for GPS, GLONASS and combined GPS/GLONASS. Figures 2 to 7 show variation of the average number of visible satellites and Dilution of Precision (DOP) values during observations collection period for GPS, GLONASS and combined GPS/GLONASS constellations.

Table 1. The average no. of visible satellites and average DOP values for tested constellations.

\begin{tabular}{|c|c|c|c|c|}
\hline Constellation & $\begin{array}{c}\text { Average no. } \\
\text { visible satellites }\end{array}$ & $\begin{array}{c}\text { Average } \\
\text { HDOP }\end{array}$ & $\begin{array}{c}\text { Average } \\
\text { VDOP }\end{array}$ & $\begin{array}{c}\text { Average } \\
\text { PDOP }\end{array}$ \\
\hline GPS & 7 & 1.094 & 1.980 & 2.266 \\
\hline GLONASS & 6 & 1.286 & 2.586 & 2.930 \\
\hline GPS/GLONASS & 14 & 0.749 & 1.340 & 1.540 \\
\hline
\end{tabular}




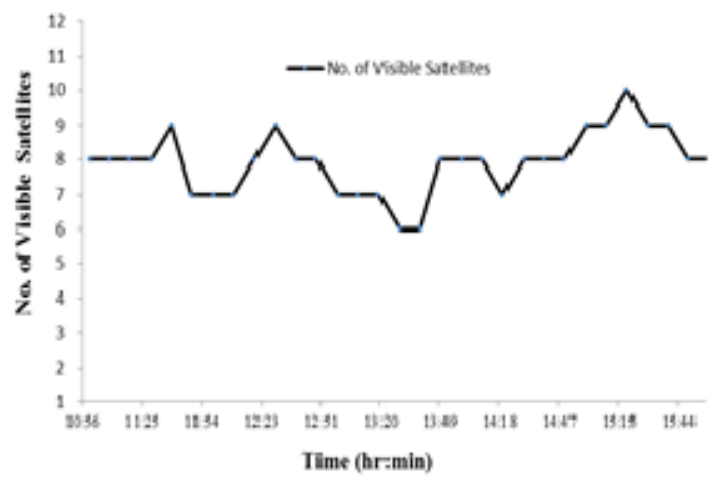

Fig_(2): Number of GPS Visible Satellites During Kinematic Test Observations Collexion Period (6/3/2017).

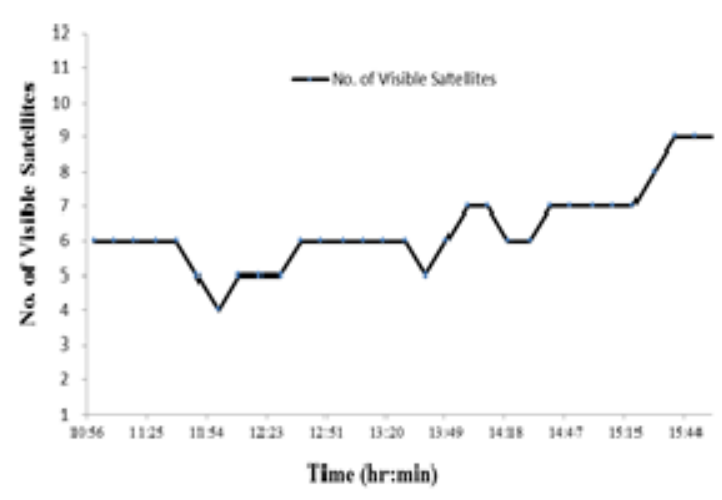

Fig,( $(9)$ i Number of GLONASS Visible Satellites During Kinematic Test Observations Collecion Period (6/3/2017).

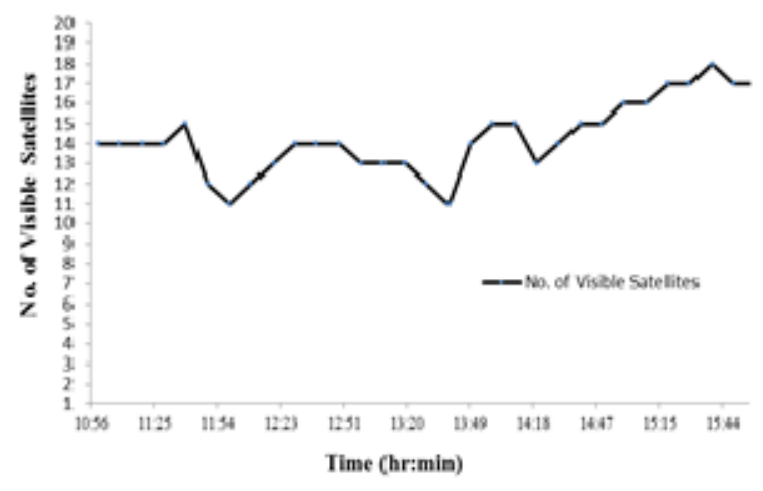

Fiz.(6): Niumber of Visible Satellites (GPS/GLONASS combined constellation) During Kinematic Test Observations Collecion Period $(6 / 3 / 2017)$

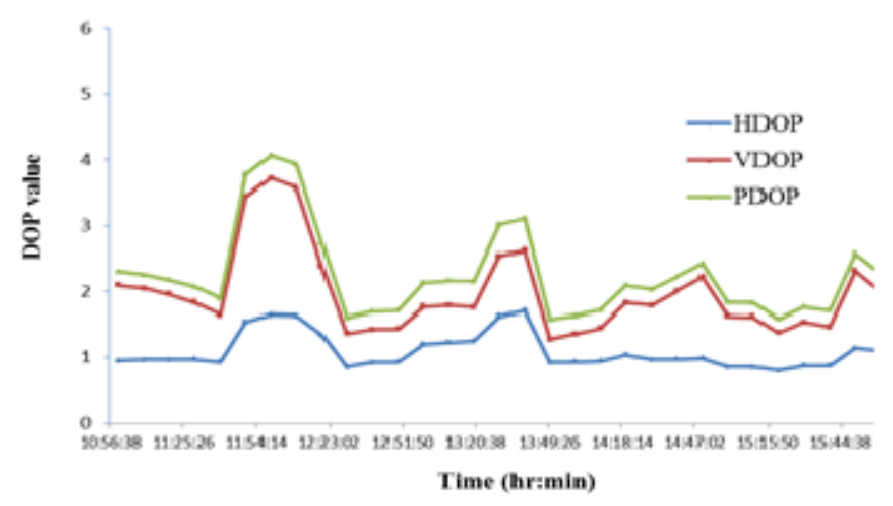

Fig. (3): Variation of GPS -DOP values (HDOP \& VDOP \& PDOP) During Kine matic Test observations collection perioe (6/3/2017).

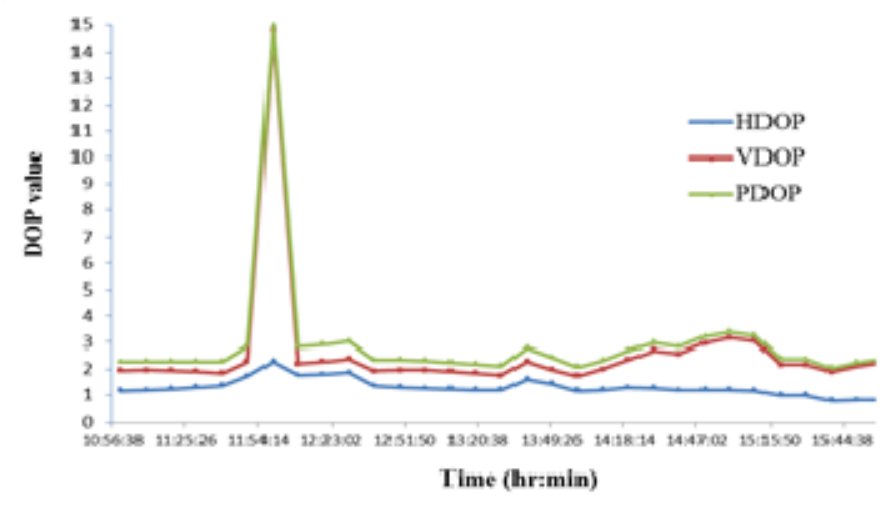

Fig- (5): Variation of GLONASS -DOP values (HDOP \& VDOP \& PDOP) During Kinematic Test observations collection period $(6 / 3 / 2017)$.

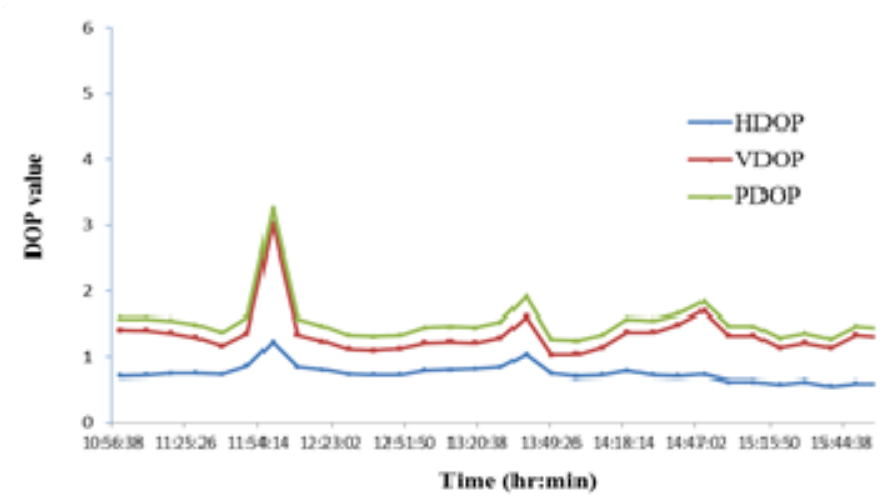

Fis. (7): Variation of combined (GPS/GLONASS) -DOP vallues) (HDOP \& VDOP \& PDOP) During Kinematic Test observations collection perisd $(6 / 3 / 2017)$.

\section{CANADIAN SPATIAL REFERENCE SYSTEM (CSRS) - PPP Service}

The Canadian Spatial Reference System (CSRS) Precise Point Positioning (PPP) service (CSRS-PPP, 2017) provides post-processed position estimates from GPS/GLONASS observation. Precise position estimates are referred to the CSRS standard North American Datum of 1983 (NAD83) as well as the International Terrestrial Reference Frame (ITRF). Single station position estimates are computed for users operating in static or kinematic 
modes using precise GPS orbits and clocks. The observations processed are selected from the submitted RINEX file in the following order:

1. L1 and L2 pseudo-range and carrier phase observations

2. L1 pseudo-range observation

An Ionospheric model is required for correction ionospheric delays from single-frequency observations. The source of ionospheric corrections selected for the L1 processing by the online application are the combined global ionospheric maps produced at 2-hour intervals in IONEX format by IGS with an accuracy of $\pm 2-8$ TECU-level (range errors in the order of $30 \mathrm{~cm}$ to $1 \mathrm{~m}$ ) (Huber and Heuberger, 2010). The L1\&L2 processing uses the L1\&L2 ionospheric-free combination of the code $\&$ phase observations and does not require input of an external source of ionospheric information. Table (2) shows the errors considered during PPP process (Rizos et al., 2012). Table (3) shows Processing algorithms for CSRS-PPP online service.

Table 2. The errors considered during PPP process (Rizos et al., 2012).

\begin{tabular}{|l|l|l|}
\hline The errors considered during PPP process \\
\hline Satellite dependent errors & Receiver dependent errors & Atmospheric modelling \\
\hline Satellite clock corrections & Receiver antenna phase centre offset & Troposphere delay \\
Satellite ephemeries & Receiver antenna phase centre & Ionosphere delay (L1 only) \\
Satellite antenna phase centre & variations & Geophysical models \\
variations & Receiver antenna phase wind-up & Solid earth tide \\
Satellite antenna phase centre offset & error & displacements \\
Satellite antenna phase wind-up error & & Ocean loading \\
& & Polar tides \\
\hline
\end{tabular}

Table 3. Processing algorithms for CSRS-PPP online service.

\begin{tabular}{|l|l|}
\hline Reference system & ITRF2008 \\
\hline Coordinate format & LLH/XYZ \\
\hline $\begin{array}{l}\text { Satellite orbit and clock } \\
\text { ephemeris }\end{array}$ & IGS \\
\hline $\begin{array}{l}\text { Satellite phase centre } \\
\text { offsets }\end{array}$ & IGS ANTEX \\
\hline $\begin{array}{l}\text { Receiver phase centre } \\
\text { offsets }\end{array}$ & IGS ANTEX \\
\hline Tropospheric model & $\begin{array}{l}\text { Dry model: Davis (GPT) (Global Pressure and Temperature data) } \\
\text { Wet model: Hopfield model (GPT) (Global Pressure and Temperature } \\
\text { data) }\end{array}$ \\
\hline Mapping function & GMF (Global Mapping Function) \\
\hline Ionospheric model & $\begin{array}{l}\text { Second-order linear ionospheric combination (for dual frequency } \\
\text { observations) } \\
\text { IGS combined global ionospheric maps (for single frequency } \\
\text { observations) }\end{array}$ \\
\hline Min. Elevation angle & $10^{\circ}$ \\
\hline GNSS System & GPS/GLONASS \\
\hline Software & CSRS-PPP \\
\hline Observation Data & $\begin{array}{l}\text { Single/dual frequency } \\
\text { Static/kinematic }\end{array}$ \\
\hline Ocean tide loading & FES 2004 (Finite Element Solution) \\
\hline
\end{tabular}




\section{RESULTS \& DISCUSSION}

\subsection{DUAL-FREQUENCY OBSERVATIONS}

Figures 8 to 10 present PPP-kinematic precision variation for the first category test (dual frequency observations) using different constellations; GPS, GLONASS and combined GPS/GLONASS.Table (4) presents statistical analysis for kinematic-PPP precision using dual frequency observations from different constellations.

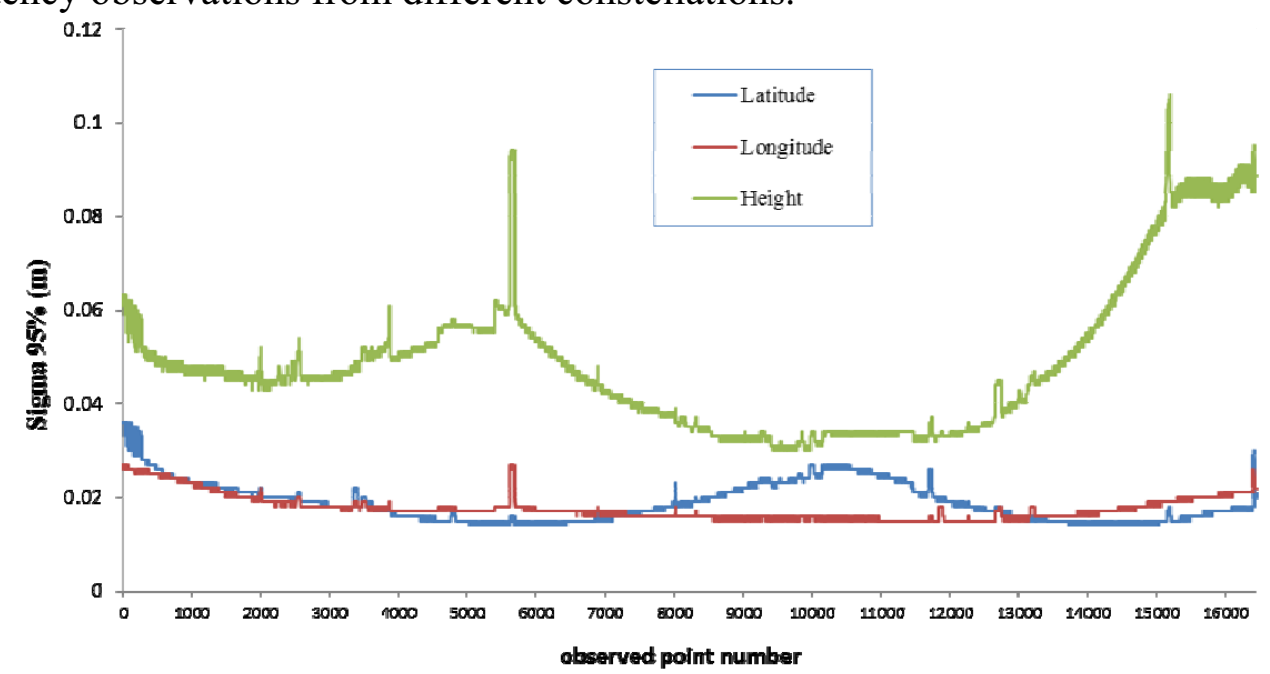

Fig. (8): Kinemattc-PPP Posittoning Precision for dual frequency GPS abservations (6/3/2017).

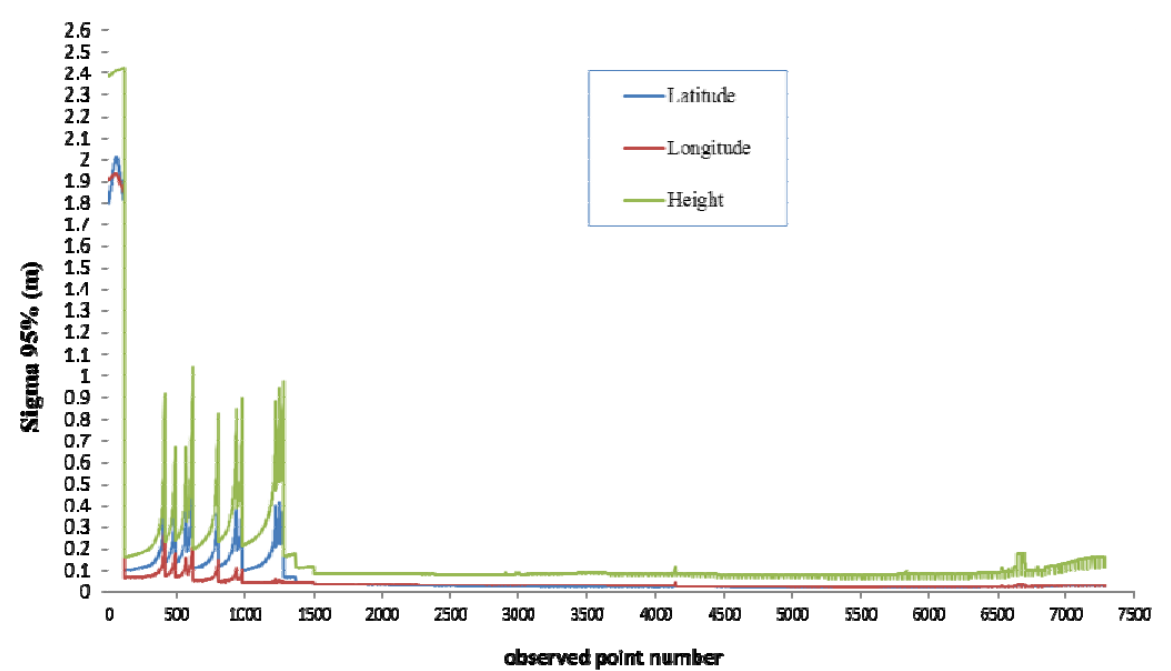

Fig. (9): Kinematte-PPPPosittoning Precision for dual frequency GLONASS observattons (6/3/2017).

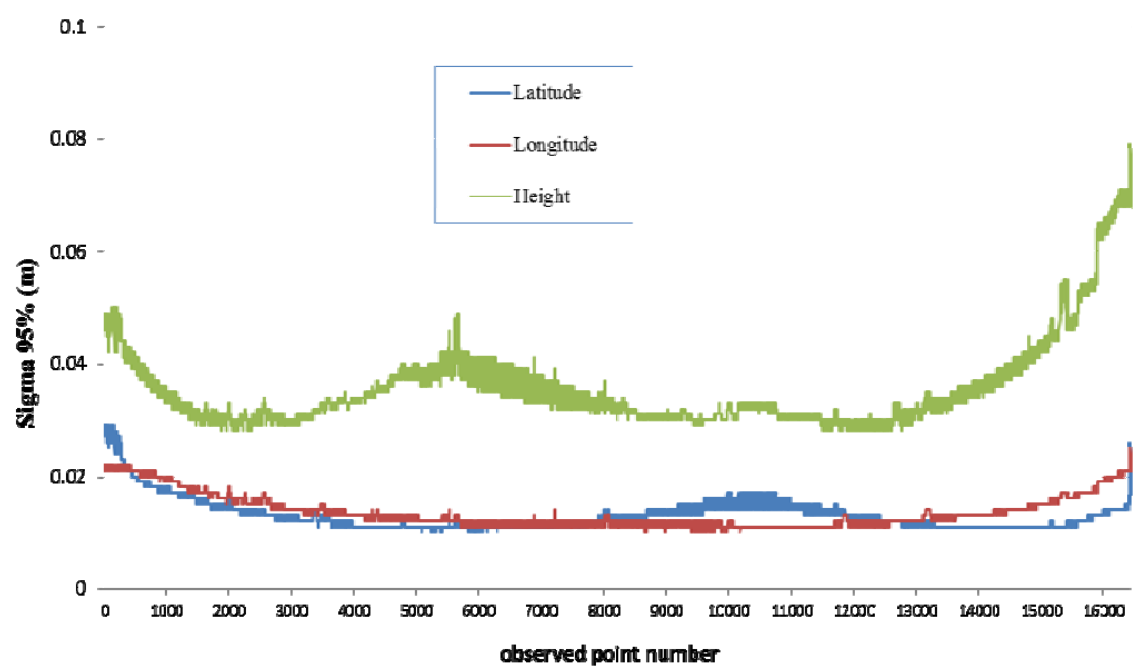

Fig. (10): Kinematic-PPP Positioning Precision for dusl frequency mixed GPS/GLONASS observations (6/3/2017). 
Table 4. Statistical Analysis for Kinematic-PPP precision variation using dual frequency observations from different constellations.

\begin{tabular}{|l|c|c|c|c|c|c|c|c|c|}
\hline Constellation & \multicolumn{3}{|c|}{ GPS } & \multicolumn{3}{c|}{ GLONASS } & \multicolumn{3}{c|}{$\begin{array}{c}\text { Combined } \\
\text { GPS/GLONASS }\end{array}$} \\
\hline Sigma (m) & $\begin{array}{c}\text { Sigma } \\
\text { latitude }\end{array}$ & $\begin{array}{c}\text { Sigma } \\
\text { longitude }\end{array}$ & $\begin{array}{c}\text { Sigma } \\
\text { height }\end{array}$ & $\begin{array}{c}\text { Sigma } \\
\text { latitude }\end{array}$ & $\begin{array}{c}\text { Sigma } \\
\text { longitude }\end{array}$ & $\begin{array}{c}\text { Sigma } \\
\text { height }\end{array}$ & $\begin{array}{c}\text { Sigma } \\
\text { latitude }\end{array}$ & $\begin{array}{c}\text { Sigma } \\
\text { longitude }\end{array}$ & $\begin{array}{c}\text { Sigma } \\
\text { height }\end{array}$ \\
\hline Maximum (m) & $\mathbf{0 . 0 3 6}$ & $\mathbf{0 . 0 2 7}$ & $\mathbf{0 . 1 0 6}$ & $\mathbf{0 . 5 9 1}$ & $\mathbf{0 . 2 8 8}$ & $\mathbf{1 . 0 3 8}$ & $\mathbf{0 . 0 2 9}$ & $\mathbf{0 . 0 2 5}$ & $\mathbf{0 . 0 7 9}$ \\
\hline Minimum(m) & $\mathbf{0 . 0 1 4}$ & $\mathbf{0 . 0 1 4}$ & $\mathbf{0 . 0 1 5}$ & $\mathbf{0 . 0 1 8}$ & $\mathbf{0 . 0 1 9}$ & $\mathbf{0 . 0 6 2}$ & $\mathbf{0 . 0 1 0}$ & $\mathbf{0 . 0 1 0}$ & $\mathbf{0 . 0 2 8}$ \\
\hline Average (m) & $\mathbf{0 . 0 1 9}$ & $\mathbf{0 . 0 1 8}$ & $\mathbf{0 . 0 4 9}$ & $\mathbf{0 . 0 4 9}$ & $\mathbf{0 . 0 3 6}$ & $\mathbf{0 . 1 2 9}$ & $\mathbf{0 . 0 1 3}$ & $\mathbf{0 . 0 1 4}$ & $\mathbf{0 . 0 3 7}$ \\
\hline St.Deviation(m) & $\mathbf{0 . 0 0 4}$ & $\mathbf{0 . 0 0 3}$ & $\mathbf{0 . 0 1 6}$ & $\mathbf{0 . 0 6 3}$ & $\mathbf{0 . 0 1 9}$ & $\mathbf{0 . 1 0 7}$ & $\mathbf{0 . 0 0 3}$ & $\mathbf{0 . 0 0 3}$ & $\mathbf{0 . 0 0 8}$ \\
\hline
\end{tabular}

\subsection{SINGLE-FREQUENCY OBSERVATIONS}

Figures 11 to 13 present PPP-kinematic precision variation for the SECOND category test (SINGLE frequency observations) using different constellations; GPS, GLONASS and combined GPS/GLONASS.Table (5) presents statistical analysis for kinematic-PPP precision using dual frequency observations from different constellations.

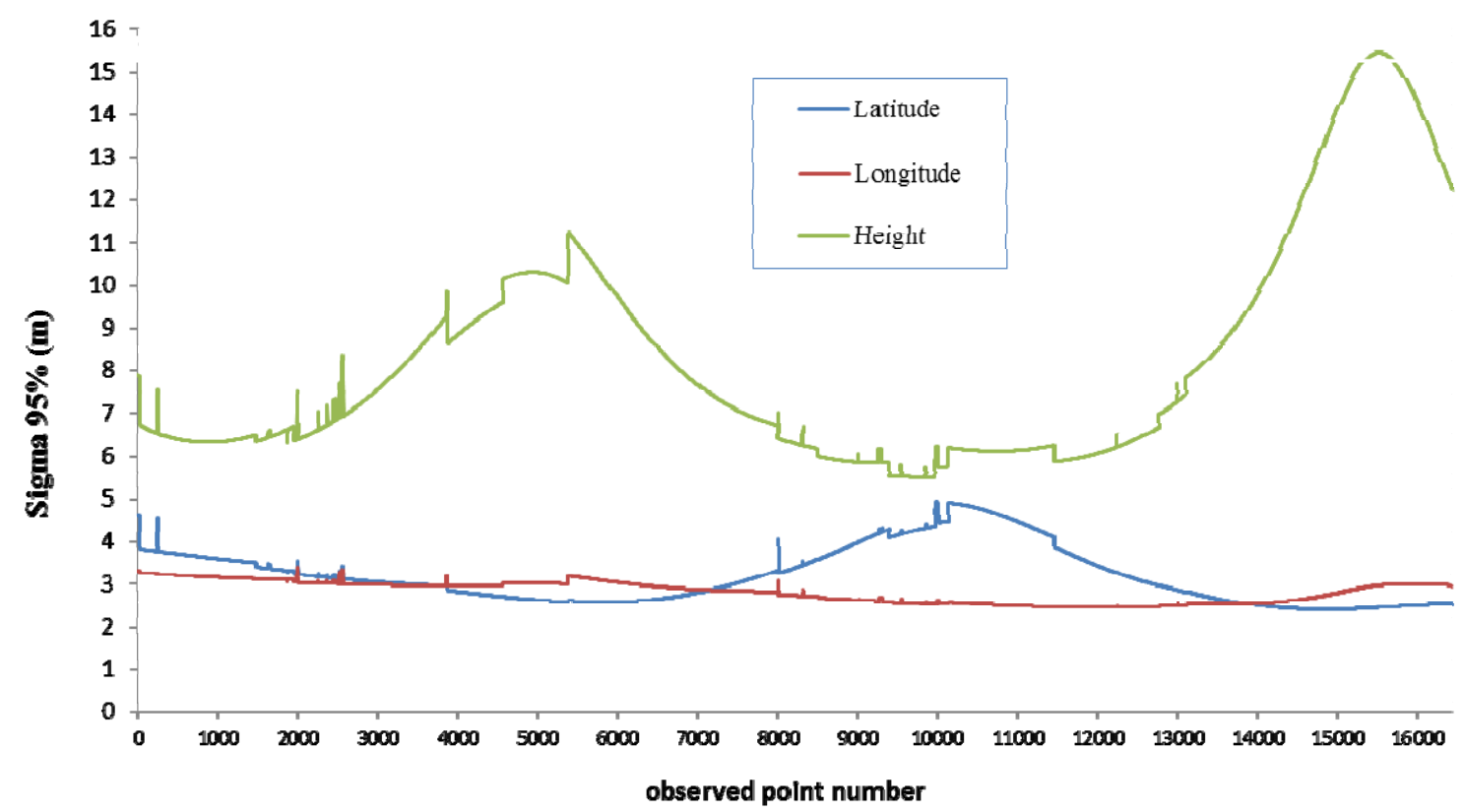

Fig. (11): Kinematic-PPP Positioning Precision for Single Frequency GPS observations (6/3/2017).

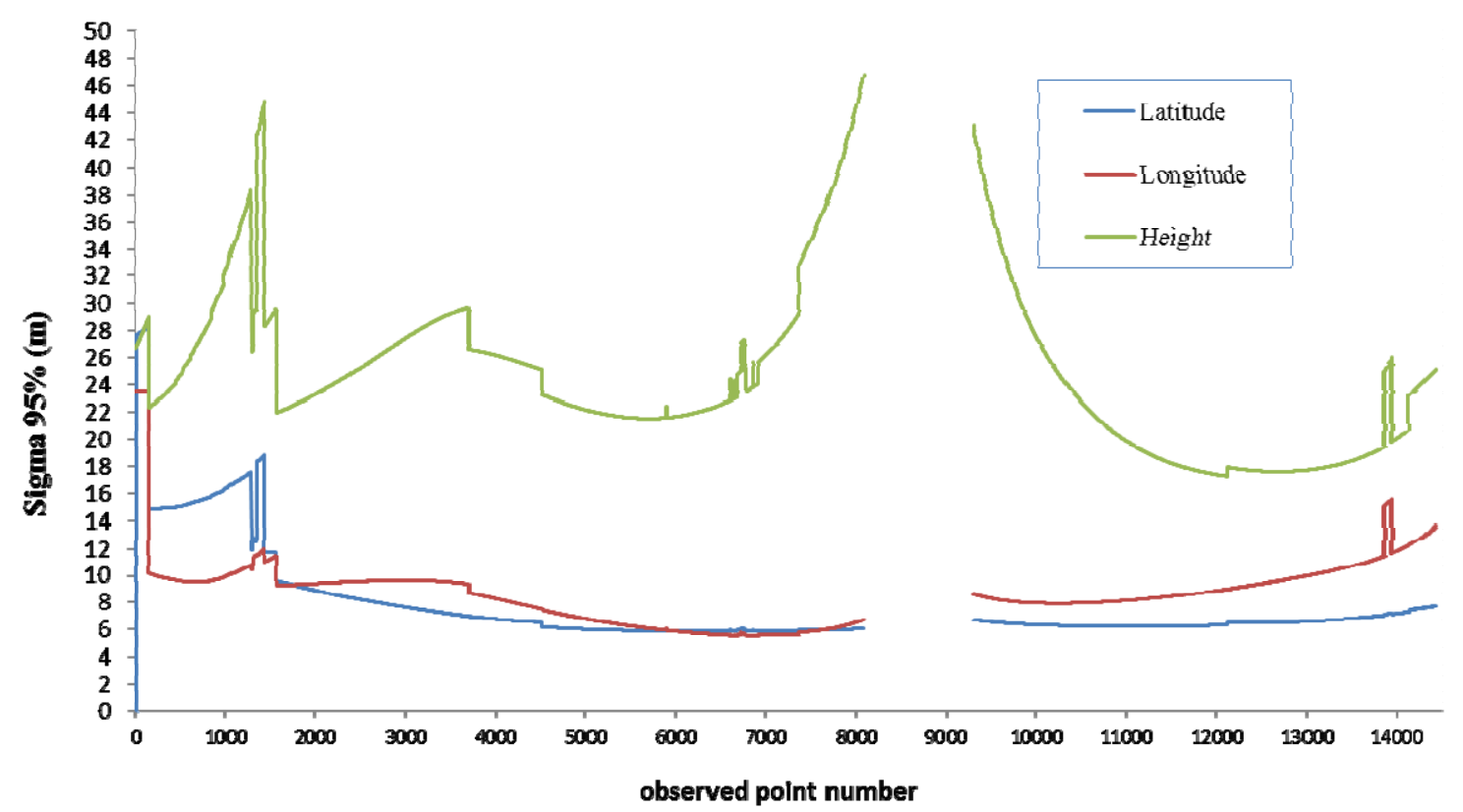

Fig. (12): Kinematic-PPP Positioning Precision for Single Frequency GLONASS observations (6/3/2017). 


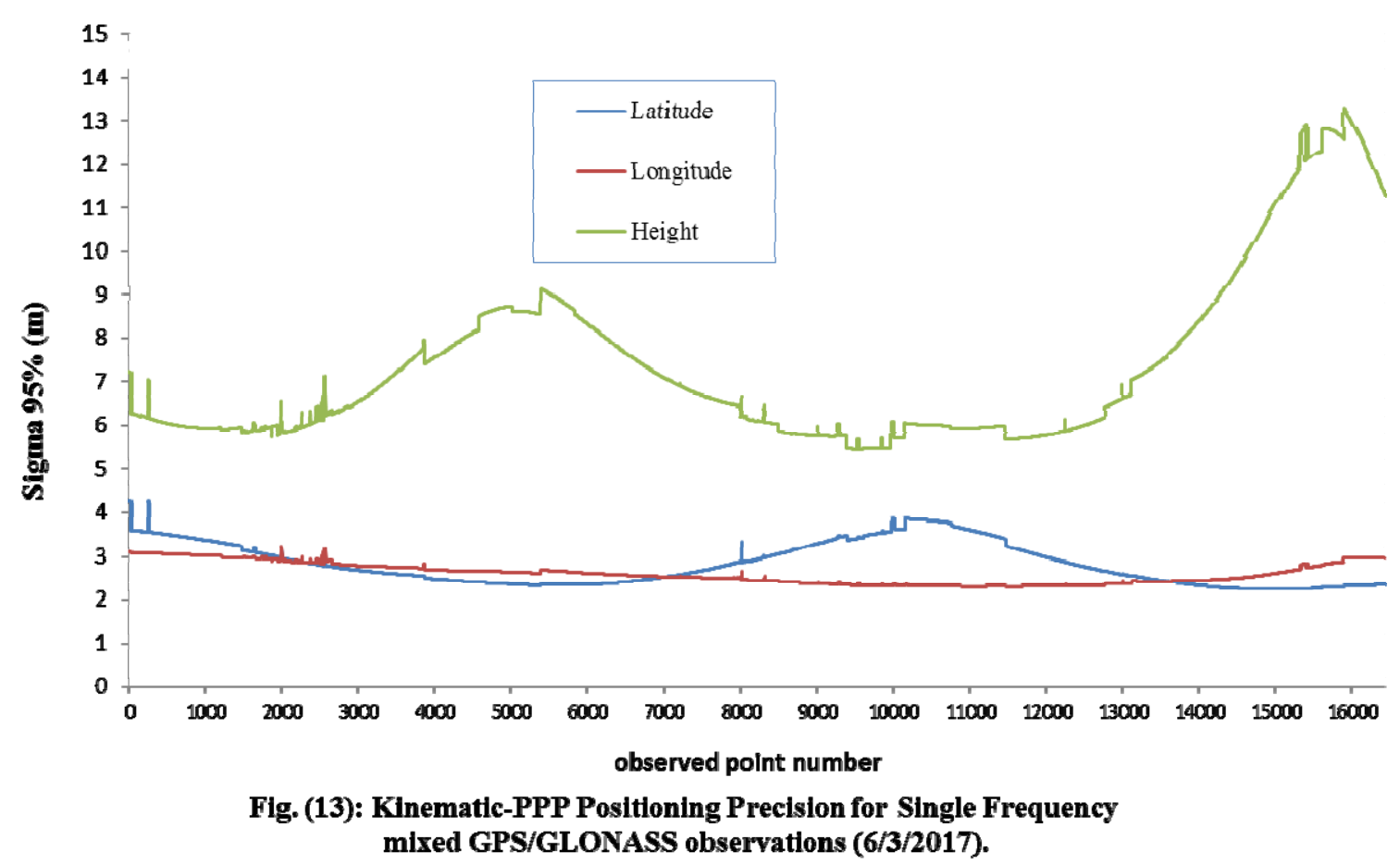

Table 5. Statistical analysis for Kinematic-PPP precision variation using single frequency observations from different constellations.

\begin{tabular}{|l|c|c|c|c|c|c|c|c|c|}
\hline Constellation & \multicolumn{3}{|c|}{ GPS } & \multicolumn{3}{c|}{ GLONASS } & \multicolumn{3}{c|}{$\begin{array}{c}\text { Combined } \\
\text { GPS/GLONASS }\end{array}$} \\
\hline Sigma (m) & $\begin{array}{c}\text { Sigma } \\
\text { latitude }\end{array}$ & $\begin{array}{c}\text { Sigma } \\
\text { longitude }\end{array}$ & $\begin{array}{c}\text { Sigma } \\
\text { height }\end{array}$ & $\begin{array}{c}\text { Sigma } \\
\text { latitude }\end{array}$ & $\begin{array}{c}\text { Sigma } \\
\text { longitude }\end{array}$ & $\begin{array}{c}\text { Sigma } \\
\text { height }\end{array}$ & $\begin{array}{c}\text { Sigma } \\
\text { latitude }\end{array}$ & $\begin{array}{c}\text { Sigma } \\
\text { longitude }\end{array}$ & $\begin{array}{c}\text { Sigma } \\
\text { height }\end{array}$ \\
\hline Maximum(m) & 4.924 & 3.39 & 15.453 & 28.33 & 23.46 & 46.814 & 4.267 & 3.227 & 13.299 \\
\hline Minimum (m) & 2.423 & 2.423 & 2.477 & 5.819 & 5.438 & 17.203 & 2.241 & 2.313 & 5.455 \\
\hline Average (m) & 3.196 & 2.818 & 8.251 & 7.806 & 8.649 & 24.77 & 2.817 & 2.599 & 7.346 \\
\hline St.Deviation(m) & $\mathbf{0 . 6 6 0}$ & $\mathbf{0 . 2 3 3}$ & 2.626 & 3.589 & 2.446 & 6.047 & $\mathbf{0 . 4 8 2}$ & $\mathbf{0 . 2 3 4}$ & 1.928 \\
\hline
\end{tabular}

This research presents a study for kinematic-PPP precsion using dual and single frequency observations from different constellations; GPS, GLONASS and combined GPS/GLONASS for hydrographic applications. Using High quality receiver (Leica Viva GS-15) dual frequency kinematc observations were collected from GPS and GLONASS constellations for $27.5 \mathrm{~km}$ track on the Nile river. GPS constellation offer more number of visible satellites (610) comparing with GLONASS number of visible satellites (4-9). The combined constellation offers more number of visible satellites (11-18) which reflects on the PDOP values. Less number of GLONASS visible satellites with bad distribution leeds to worse PDOP and consequently bad precision for kinematic-PPP precision as shown in figures 9 and 12. GPS offers better PDOP values, so it provides better precision. Kinematic-PPP using Combined constellation offers better preicion than each cconstellation solely as the solution is improved using GLONASS satellites.

Kinematic-PPP solution using dual frequency observations offers much better precision than the solution with single frequency observations. The effect of the ionospheric delay is nearly eliminated using dual frequency observations (kunches and klobuchar, 2001) while it is partially eliminated using single frequency observations where the mitigation is using IGSGlobal Ionospheric Map (IGS-GIM). The effect of mitigation the ionospheric delay is highly 
marked when the observations were collected in near equtorial geographic regions (Aswan, Egypt) where the ionospheric acivity is high.

Concerning kinematic-PPP using dual frequency observations; GPS offers average precision of $18.5 \mathrm{~mm}, 49 \mathrm{~mm}$ for $\mathrm{Hz}$. and vertical coordinates respectively. GLONASS offers average precision of $43.5 \mathrm{~mm}$ horizontally and $129 \mathrm{~mm}$ vertically. Combined GPS/GLONASS constellation offers average precision of $13.5 \mathrm{~mm}$ horizontally and $37 \mathrm{~mm}$ vertically. Concerning kinematic-PPP using single frequency observations; GPS offers average precision of $3.00 \mathrm{~m}, 8.30 \mathrm{~m}$ for $\mathrm{Hz}$. and vertical coordinates respectively. GLONASS offers average precision of $8.4 \mathrm{~m}$ horizontally and $25 \mathrm{~m}$ vertically. Combined GPS/GLONASS constellation offers average precision of $2.70 \mathrm{~m}$ horizontally and $7.3 \mathrm{~m}$ vertically. It is clear that kinematic-PPP precision using single frequency observations is much worst than dual frequency observations precision by an average of $100 \%$. This is due to the different mitigation techniques for the ionospheric delay. The single frequency observations precision for kinematic-PPP could be improved using regional ionospheric model to mitigate the ionospheric delay instead of IGS-GIM which is the scope of ongoing research.

\section{CONCLUSIONS}

This research presents an evaluation study for the variability of kinematic-PPP precision for hydrography using single \& dual frequency observations based on different constellations; GPS, GLONASS and combined (GPS/GLONASS). Combined GPS/GLONASS constellation using dual frequency observations offers average precision of $13.5 \mathrm{~mm}$ horizontally and 37 $\mathrm{mm}$ vertically. GPS constellation (dual frequency observations) offers better number of visible satellites and DOP values comparing with GLONASS which improves kinematic-PPP precision by $60 \%$. Combined constellation (dual frequency observations) offers more number of visible satellites and better DOP values which improves kinematic-PPP precision by $26 \%$ over GPS constellation and 71\% over GLONASS constellation.Combined GPS/GLONASS constellation using single frequency observations offers average precision of $2.7 \mathrm{~m}$ horizontally and $7.3 \mathrm{~m}$ vertically. GPS constellation (single frequency observations) improves kinematic-PPP precision by $65 \%$ over GNLONASS constelation. Combined constellation (single frequency observations) improves kinematic-PPP precision by $11 \%$ over GPS constellation and $69 \%$ over GLONASS constellation. Dual frequency observations offers better precision for kinematic-PPP over single frequency observations by an average of $100 \%$ improvement ratio. The single frequency observations precision for kinematic-PPP could be improved using regional ionospheric model to mitigate the ionospheric delay especially in near equatorial geographic regions which have the highest activity for the ionosphere.

\section{REFERENCES}

Abdallah, A., Schwieger, V. (2015). "Kinematic Precise Point Positioning (PPP) Solution for Hydrographic Applications”. FIG Congress 2015, 17-21 May, Sofia, Bulgaria.

Abdallah, A. (2016). "Hydrography over River Nile Using GPS Technology, A Case Study: Aswan City, Egypt". Research and Technology Development for Sustainable Water Resources Management (REDWARM) conference. Egypt. December 2016.

Bisnath S., Gao Y. (2008). Current State of Precise Point Positioning and Future Prospects and Limitations. International Association of Geodesy Symposia, Vol. 133 pp. 615-623, 2008.

Cai, C., Gao,Y (2013)." GLONASS-based precise point positioning and performance analysis", in: Advances in Space Research 51 (2013) 514-524. 
CSRS-PPP (2017). Canadian Spatial Reference System (CSRS) Precise Point Positioning (PPP) service. http://www.geod.nrcan.gc.ca/products-produits/ppp_e.php. Accessed $(10 / 3 / 2017)$.

Geng J, Teferle FN, Meng X, Dodson AH (2010). Kinematic precise point positioning at remote marine platforms. GPS Solutions. 14(4): 343-350.

GLONASS (2017). GLONASS constellation status. Federal space agency-information analytical centre. https://glonass-iac.ru/en/GLONASS/. Accessed (5/3/2017)

GoogleEarth (2017). GoogleEarth software. https://www.google.com.eg/intl/ar/earth/. Accessed (5/3/2017).

Huber, K. and Heuberger, F. (2010)."PPP: Precise Point Positioning - Constraints and Opportunities". FIG Congress 2010 (Facing the Challenges - Building the Capacity) Sydney, Australia, 11-16 April 2010

IHO (2005). International Hydrographic Organization. Manual on Hydrography. Publication C-13. https://www.iho.int/iho_pubs/CB/C-13/. Acsessed (5/12/2017)

Kunches, J. M. and Klobuchar, J. A. (2001). Eye on The Ionosphere: GPS after SA. GPS Solutions 4(3), PP. 52-54.

Leica Viva (2017). Leica Geosystems products. http://leica-geosystems.com/products/gnsssystems/receivers/leica-viva-gs10-gs25. Accessed (5/3/2017).

Marreiros, J. (2012). "Kinmeatic GNSS Precise Point Positioning: Application to Marine Platforms". Ph.D. thesis. University of Porto, Portugal. 2012.

Rizos, C., Janssen, V., Roberts, C., Grinter, T. (2012). Precise Point Positioning: Is the Era of Differential GNSS Positioning Drawing to an End?. FIG Working Week, 6-10 May, Rome, Italy

TEQC (2017). TEQC-UNAVCO tutorial. http://facility.unavco.org/software/teqc/doc/UNAVCO_Teqc_Tutorial.pdf. Accessed $(15 / 3 / 2017)$.

Tolman, B.W., Kerkhoff, A., Rainwater, D., Munton, D., Banks, J.(2010)" Absolute precise kinematic positioning with GPS and GLONASS", in: Proc. ION GNSS 2010, Portland, Oregon, pp. 2565-2576, September 21-24, 2010.

Zumberge, J. F., M. B. Heflin, D. C. Jefferson, M. M. Watkins, and F. H. Webb (1997): Precise Point Processing for the Efficient and Robust Analysis of GPS Data from Large Networks, J. Geophys. Res., 102(B3), 5005-5017.

Received: 2017-09-25,

Reviewed: 2017-11-23 and 2018-01-29,

Accepted: 2018-02-02. 